\title{
The Meso Analysis on the Damage of the Crossover Jointed Rock Mass under the Uniaxial Compression
}

\author{
Bing SUN ${ }^{1, a}$, Haifeng ZHANG ${ }^{1, b}$, Qiuyang ZHANG ${ }^{1, c}$, Sheng ZENG ${ }^{2, d}$ \\ ${ }^{1}$ Institute of Urban Construction, University of South China ,Hengyang 421001 ,China \\ ${ }^{2}$ School of Nuclear Resources Engineering,University of South China ,Hengyang 421001,China \\ asunbingzs@126.com , b153062295@qq.com ,'389236086@qq.com ,'zeng0808@126.com
}

Keywords: rock mechanics; crossover jointed rock; uniaxial compression; numerical simulation Abstract: The rock structure is extremely complex, it is difficult to reflect the mechanical properties and the relevant failure mechanisms truly under loads whatever by the theoretical analysis or the laboratory test. In order to analyze the damage characteristics of the crossover jointed rock mass from the microscopic point, the discrete method PFC2D was used to simulate the damage mechanism in the assured jointed rock numerically under Axial compression. The results show that when the angle of the main joint is consistent with the direction of the load, the varying angle between the minor joint and the main joint has rarely influence on the stress-strain curve of the rock mass, the stress when the first fine crack comes up and the peak; when the angle between the minor joint and the main joint is not changing, the peak value gradually reduces as the direction angle between the main joint and the load varying from $0^{\circ}$ to $90^{\circ}$; when the peak comes up, the direction angle between the main joint and the load is $45^{\circ}$ or $90^{\circ}$, the varying angle between the minor joint and the main joint has rarely influence on the development of the number of new fine cracks, while the angle between the main crack and the load is $0^{\circ}$, the impact on the development of the number of new fine cracks is obvious.

\section{Introduction}

The most rocks in nature contain the joints whose rules are different. The jointed crack has been the most critical factor in the influence on the mechanical properties of the rock. The deformation mechanism of the jointed rock mass is also the current problem needing to be resolved in the actual rock engineering. So the study on the failure mechanism of the jointed rock is greatly significant. Through the laboratory model testing and numerical analysis, scholars all over the world gradually studied on the failure process of the rock from the intact rock to the single joint, then to a few joints. Such as in experiments, by the compression test on a single fracture of the jointed rock, Brace et al ${ }^{[1]}$. got the solution that there is a certain angle of the deviation extension in the crack at the pointed end. Bei-chuan Han et $\mathrm{al}^{[2]}$ proposed the summation formula about the amount of crack damage of the jointed rock mass. Wei-zhong $\mathrm{Chen}^{[3]}$ studied the laws about the expansion and penetration of the different closure cracks in the rock under the different loading forms. A. V. Dyskin, M. F. Ash by et $\mathrm{al}^{[4-5]}$ studied the laws about the crack development and stress-strain variation of the jointed rock with the different angles of center under the multi-level loading. Bo Zhang et al ${ }^{[6-7]}$ used the similar material models to investigate the failure mechanism of the filling jointed rock and the crossover jointed and fractured rock under the uniaxial compression. Through the rock compression test, Peng-zhi Pan et al ${ }^{[8]}$ established the function about the effect with different sizes and shapes and the development process of rock failure. Xiao-ping Zhang et al ${ }^{[9]}$ studied experimentally the crack propagation of sheet rock. Xiao-ping Yuan et al. ${ }^{[10]}$ established the elastic-plastic fracture model for the non-penetrated jointed rocks under the compression loads based the D-P standard. In the numerical simulation research, Xue-bing Wang ${ }^{[11]}$ used FLAC to simulate the effect of the jointed rock inclination on the anisotropical peak strength of the rock samples, the mechanical behavior and the pattern of the shear band. It indicates some rules about the inclination to the rock peak under uniaxial compression, the stress and strain and the crack extension.

Because the theoretical analysis of the mechanical properties about joints under compression and the indoor models above are based on the numerous assumptions, it is difficult to reflect the mechanical properties and failure mechanism of the rock itself in fact the discrete finite element 
PFC2D module is used to simulate the rocks which contain the crossover fractured joints under the uniaxial compression, and study the corresponding damage mechanisms.

\section{The microscopic damage model of the crossover jointed rock}

\subsection{Model establishment}

When the bedding, schistosity, joints, and faults with weak coupling are cut down in the rock mass, it makes the rock mass become a non-uniform, non-continuous, anisotropic geological body. It is not necessary to simulate the actual situation, and it may have many difficulties. In the simulating process of rock compression, PFC uses the method named central difference to process the integral operation to the equation of particles motion during the whole time domain, and to ensure the accuracy and stability of the solution. PEC2D assumes that the simulation size of the rock compressed is $80 \mathrm{~mm} \times$ $80 \mathrm{~mm}$ and the rock is elastoplastic, the crossover crack is penetrated, the thickness is $0.25 \mathrm{~mm}$, the length of the main crack named $\mathrm{L}_{1}$ is $30 \mathrm{~mm}$, the length of the minor crack named $\mathrm{L}_{2}$ is $20 \mathrm{~mm}, \mathrm{~L}_{1}$ and $\mathrm{L}_{2}$ share each other equally by the intersection. The total number of rock particles which are generated in this simulation process is about 8000, the linear model of parallel bonding is used among the particles, the linear and contact model is used between the particle and the wall.In order to understand the failure mechanism of the crossover jointed rock under the uniaxial compression, we set that $\theta$ is the angle between the main joint and the loading direction, $\gamma$ is the angle between the main joint and the minor joint. Based on the effect of the crossover primary and minor joints on the rock damage, the eighteen kinds of experimental conditions are carried out as shown in table 1 . The schematic diagram of the numerical simulation of the uniaxial compression test is shown in figure 1.

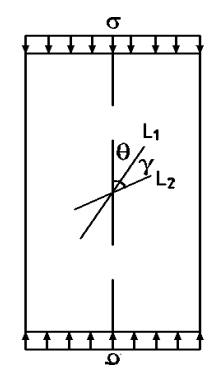

Fig. 1 The schematic diagram of the uniaxial compression test on the crossover jointed rock

Table1 The working conditions of the simulating test

\begin{tabular}{|c|c|c|c|c|c|c|c|c|}
\hline $\begin{array}{l}\text { Working } \\
\text { Condition }\end{array}$ & $\begin{array}{c}\text { The angle } \\
\text { between the } \\
\text { main crocks } \\
\theta /\left(^{\circ}\right)\end{array}$ & $\begin{array}{c}\text { The angle } \\
\text { between the } \\
\text { minor crocks } \\
\gamma /\left(^{\circ}\right)\end{array}$ & $\begin{array}{c}\text { Working } \\
\text { Condition }\end{array}$ & $\begin{array}{c}\text { The angle } \\
\text { between the } \\
\text { main crocks } \\
\theta /\left({ }^{\circ}\right)\end{array}$ & $\begin{array}{c}\text { The angle } \\
\text { between the } \\
\text { minor crocks } \\
\gamma /\left({ }^{\circ}\right)\end{array}$ & $\begin{array}{l}\text { Working } \\
\text { Condition }\end{array}$ & $\begin{array}{c}\text { The angle } \\
\text { between the } \\
\text { main crocks } \\
\theta /\left(^{\circ}\right)\end{array}$ & $\begin{array}{c}\text { The angle } \\
\text { between the } \\
\text { minor crocks } \gamma / \\
\left({ }^{\circ}\right)\end{array}$ \\
\hline 1 & \multirow{6}{*}{0} & 15 & 7 & \multirow{6}{*}{45} & 15 & 13 & \multirow{6}{*}{90} & 15 \\
\hline 2 & & 30 & 8 & & 30 & 14 & & 30 \\
\hline 3 & & 45 & 9 & & 45 & 15 & & 45 \\
\hline 4 & & 60 & 10 & & 60 & 16 & & 60 \\
\hline 5 & & 75 & 11 & & 75 & 17 & & 75 \\
\hline 6 & & 90 & 12 & & 90 & 18 & & 90 \\
\hline
\end{tabular}

\subsection{Simulation parameters}

In PFC calculations, it does not need to define the macroscopic constitutive relation and the corresponding parameters to the material, it simply needs to define the geometry of the particle and mechanical parameters, the physical and mechanical parameters of the rock in this simulation are shown in table 2 and table 3. 
Table 2 The parameters of rock model

\begin{tabular}{|c|c|c|c|c|c|c|c|c|c|}
\hline $\begin{array}{c}\text { The parameter } \\
\text { of rock }\end{array}$ & $\begin{array}{l}\text { The specific } \\
\text { gravity of the } \\
\text { particles } \\
\left(\mathrm{kg} / \mathrm{m}^{3}\right)\end{array}$ & $\begin{array}{c}\text { The radius of the } \\
\text { particle } / \mathrm{mm}\end{array}$ & $\begin{array}{l}\text { The void } \\
\text { ratio }\end{array}$ & $\begin{array}{c}\text { The friction } \\
\text { coefficient } \\
\mu\end{array}$ & $\begin{array}{l}\text { The shear } \\
\text { stiffness } \\
\mathrm{kn} /(\mathrm{n} / \mathrm{m})\end{array}$ & $\begin{array}{c}\text { The normal } \\
\text { stiffness } \\
\mathrm{kn} /(\mathrm{n} / \mathrm{m})\end{array}$ & $\begin{array}{c}\text { The normal } \\
\text { stiffness with } \\
\text { parallel bonding } \\
\mathrm{kn} /(\mathrm{n} / \mathrm{m})\end{array}$ & $\begin{array}{c}\text { The shear } \\
\text { stiffness with } \\
\text { parallel bonding } \\
\mathrm{kn} /(\mathrm{n} / \mathrm{m})\end{array}$ & $\begin{array}{c}\text { The plastic } \\
\text { damping }\end{array}$ \\
\hline $\begin{array}{c}\text { The value of } \\
\text { the } \\
\text { parameter }\end{array}$ & 2600 & $0.03 \sim 0.05$ & 0.08 & 0.25 & $5 \times 10^{7}$ & $1 \times 10^{8}$ & $1 \times 10^{8}$ & $5 \times 10^{7}$ & 0.5 \\
\hline
\end{tabular}

Table 3 The parameters of joint model

\begin{tabular}{ccc}
\hline $\begin{array}{c}\text { The parameter of the joint rock } \\
\text { mass }\end{array}$ & $\begin{array}{c}\text { The normal stiffness } \\
\mathrm{kn} /(\mathrm{n} / \mathrm{m})\end{array}$ & The shear stiffness $\mathrm{kn} /(\mathrm{n} / \mathrm{m})$
\end{tabular}$\quad$ The friction coefficient $\mu$

\section{The analysis on the damage of the crossover jointed rock mass}

This simulation uses the displacement loading control, the loading speed is $0.12 \mathrm{~mm} / \mathrm{min}$, Rock meso structure is very complicated, it is a structural material between the elastoplastic and brittle material, under the uniaxial compression, the mechanical properties of the crossover joint can change a lot. We only consider the changes of a short failure process before and after the peak, but without considering the residual energy after the peak. The stress-strain relationship in the entire process is shown in figure 2 to figure 4, the values of the peak in different angles are shown in figure 5, the values of stress when the first fine crack appears are shown in figure 6 , the amount of the fine cracks when the peak reaches is shown figure 7 .

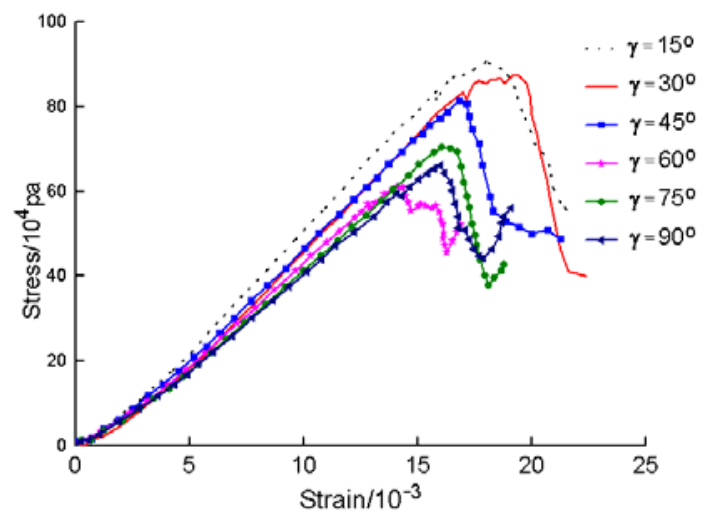

Fig. 2 The stress-strain curve when $\theta=0^{\circ}$

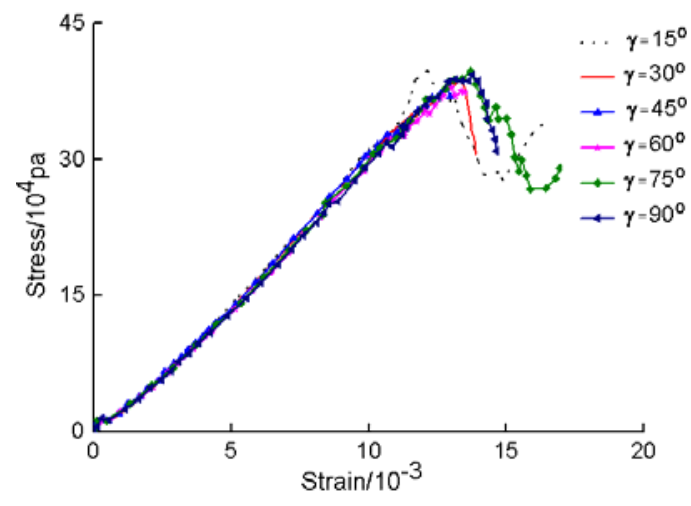

Fig. 4 The stress-strain curve when $\theta=90^{\circ}$

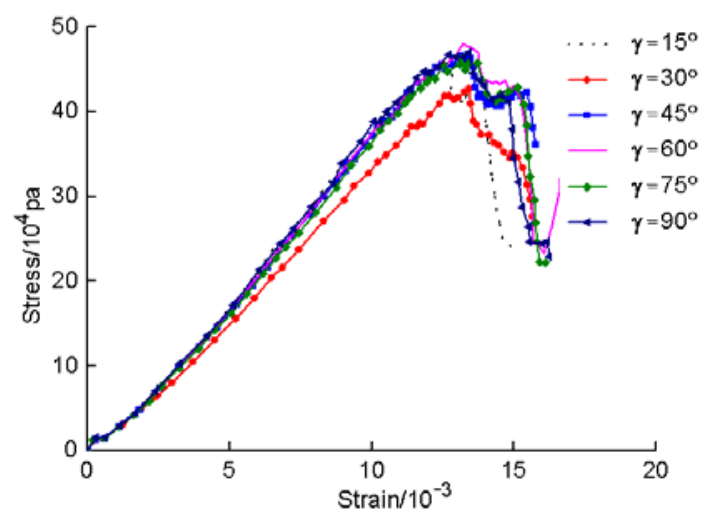

Fig. 3 The stress-strain curve when $\theta=45^{\circ}$

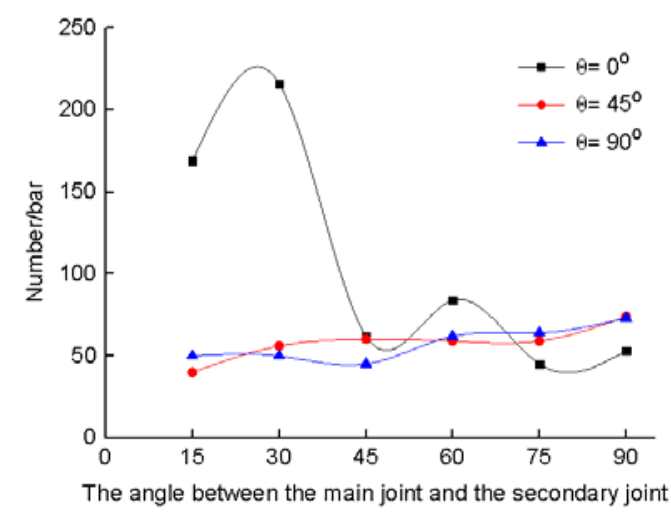

Fig. 5 the amount of the fine cracks when the peak reaches 
From the figure 2 to figure 4, when the angle $\theta$ between the main joint and the loading direction is $0^{\circ}$, at the early time when the peak comes, as the angle $\gamma$ between the minor joint and the main joint increasing from $15^{\circ}$ to $90^{\circ}$ in constant gradient, the stress intensity increases successively, and the values of strain are different when the peak appears. It shows that when the angle $\theta$ between the main joint and the loading direction is $0^{\circ}$, the minor joint in crossover jointed rock has a significant effect on the mechanical properties of the rock mass. But when the angle between the main crack and the loading direction is $45^{\circ}$ or $90^{\circ}$, at the early time when the peak comes, as the angle $\gamma$ between the minor joint and the main joint increasing from $15^{\circ}$ to $90^{\circ}$ in constant gradient, the corresponding stress-strain curves coincide within a certain range, and the values of the strain of the curve peak are also very close. It shows that when the angle $\theta$ between the main joint and the loading direction is $45^{\circ}$ or $90^{\circ}$, the minor joint in crossover jointed rock has rarely effect on the mechanical properties of the rock mass.

From the figure 5, we can see that when the angle $\theta$ between the main joint and the loading direction is $0^{\circ}$, as the angle $\gamma$ between the minor joint and the main joint increasing from $15^{\circ}$ to $90^{\circ}$, there is not regular, that is to say, when $\theta$ is $0^{\circ}$, the number of the cracks is not regular, as each fine crack appearing, its developing length is not the same, either are the propagation directions. So the appearance of the cracks is random in this dynamical balance process, but when $\theta=45^{\circ}$ or $\theta=90^{\circ}$, the number of the fine cracks is stabilized. It can prove that the development of the fine cracks is more uniform, the influence of each fine cracks appearing on the mechanical properties of rock is basically similar.

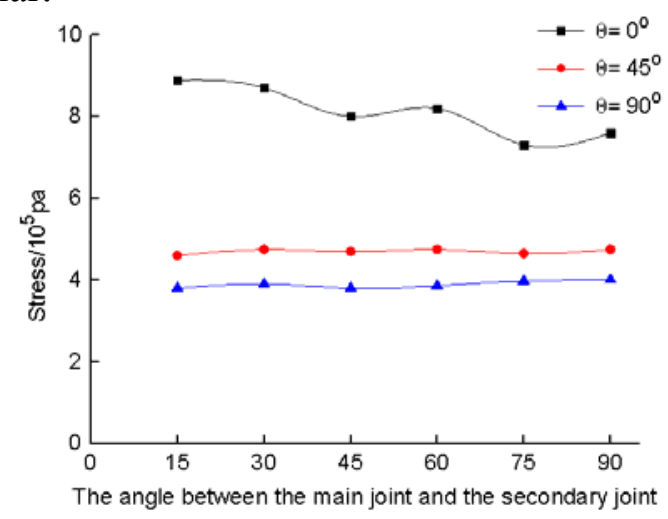

Fig.6 The values of the peak in different angles

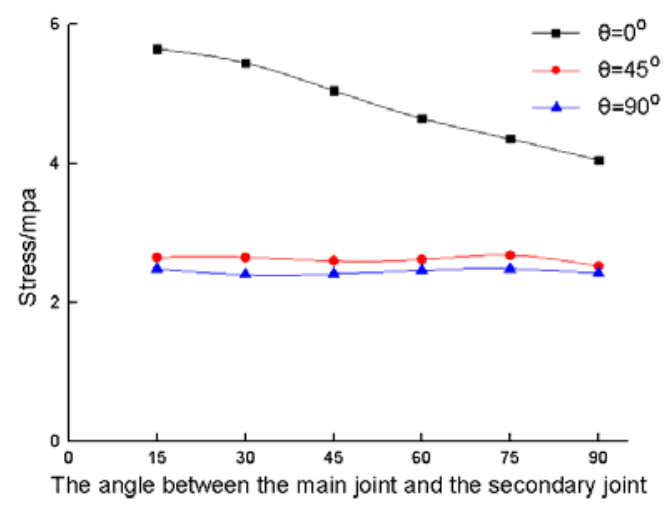

Fig.7 The value of the stress when the first fine crack appears

From the figure 6 and figure 7, we can see that when the angle $\theta$ between the main joint and the loading direction is $0^{\circ}$, as the angle $\gamma$ between the minor joint and the main joint increasing from $15^{\circ}$ to $90^{\circ}$, the corresponding value of the peak decreases, so does the value of the stress when the first fine crack appears. But when $\theta=45^{\circ}$ or $\theta=90^{\circ}$, the corresponding value of the peaks is stabilized, so is the value of the stress when the first fine crack appears. They do not change as the $\gamma$ varying. When the main crack direction and the loading direction do not change, the value of the peak and the value of the stress when the first fine crack appears are maximum when the angle between the main joint and the minor joint is $90^{\circ}$. It has the most compressive strength when the angle between the main joint and the minor joint is $90^{\circ}$. With the angle between the main joint and the loading direction increasing from $0^{\circ}$ to $90^{\circ}$, the value of the peak and the value of the stress when the first fine crack appears decrease. When the first fine crack appears, the stress when $\theta=45^{\circ}$ and that of when $\theta=90^{\circ}$ are very close. It shows that the main joint can influence on the mechanical properties of the rock mass.

\section{Conclusion}

(1) If the angle between the minor joint and the main joint changes, it has a little influence on the mechanical properties of the rock mass. When the main joint direction is consistent with the loading direction, the change of angle between the minor crack and the main crack has a little influence on the 
strain-stress curve of the rock mass before the peak appearing, the stress when the first fine crack appears and the value of the peak.

(2) The angle between the main joint and the loading direction has a significant effect on the mechanical properties of the rock mass. When the angle of main and minor joint do not change, if the angle between the main joint and the loading direction increases from $0^{\circ}$ to $90^{\circ}$, the value of the peak will decrease.

(3) When the peak appears, if the angle between the main joint and the loading direction is $45^{\circ}$ or $90^{\circ}$, the change of angle between the minor joint and the main joint will have a little influence on the development of the new fine cracks. But it has an opposite influence if the angle between the main crack and the loading direction is $0^{\circ}$. The development of the fine crack is random.

\section{References}

[1] BEACE W, BYERLEE J. Recent experimental studies of brittle facture rocks[C]//Proceedings of the Eighth Symposium on Rock Mechanic. Minnesota: American Rock Mechanics Assonciation, 1967:57-81.

[2] Bei-chuan Han, Si-jing Wang. A kind of method to calculate the damage tensor of joints systems in serial groups[J]. Chinese Journal of Rock Mechanic and Engineering, 1993, 12(01):46-54.(In Chinese)

[3] Wei-zhong Chen, Shu-cai Li, Xiang-bo Qiu, et al. Rock crack propagation experiment and numerical analysis[J]. Chinese Journal of Rock Mechanic and Engineering, 2003, 22[01]: 18-23.(In Chinese)

[4] Dyskin AV, Germanovich N. A model of crack growth in micro cracked rock [J]. lnt J. Rock Mech. Min. Sci. Geomech Abstr. 1993, 30(7): 813-820.

[5] Ashby MF, Hallam SD. The failure of birttle soilds ontaining small cracks under compressive stress states[J]. Acta Metall. 1986, 34(3): 497-510.

[6] Bo Zhang, Shu-cai Li, Dun-fu Zhang, et al. The test and fracture damage research on the specimen containing the similar materials filling the rocky body joints under the uniaxial compression[J]. Rock and Soil Mechanics, 2012, 339(06): 1647-1652.(In Chinese)

[7] Bo Zhang, Shu-cai Li, Xue-ying Yang, et al. The test on the specimen containing the crossover fractured rock under the uniaxial compression[J]. Rock and Soil Mechanics, 2012, 33(12): 3674-3679. (In Chinese)

[8] Peng-zhi Pan, Hui Zhou, Xia-ting Feng. The research on the influence of the loading conditionson the failure process of the different-scale rocks under the uniaxial compression[J]. Chinese Journal of Rock Mechanic and Engineering, 2008, 27(S2): 3636-3642.(In Chinese)

[9] Xiao-ping Zhang, Si-jing Wang, Geng-you Han, et al. The experimental study on the crack extension under the uniaxial compression[J]. Chinese Journal of Rock Mechanic and Engineering, 2011,30(09): 1772-1781.(In Chinese)

[10] Xiao-ping Yuan, Hong-yan Liu, Qiao Wang. Research on the elastic-plastic fracture model and the plastic zone of rock tip containing the part penetrating jointed rock under the uniaxial compression[J]. Rock and Soil Mechanics, 2012, 33 (06):1679-1688.(In Chinese)

[11] Xue-bing Wang. The numerical models illustrating the influence of the inclination angle of the joint on the deformation damage of the single jointed rock specimen[J]. Journal of Sichuan University (Engineering science), 2006, 38(02): 24-29.(In Chinese) 